УДК 343

\title{
О.А. Максимов
}

\section{О СОВРЕМЕННОМ НАЗНАЧЕНИИ УГОЛОВНОГО ПРОЦЕССА РОССИЙСКОЙ ФЕДЕРАЦИИ}

В статье рассматривается современное назначение российского уголовного процесса как способа реализации конституционно-определенных задач государства. Из многообразия подходов к определению предмета исследования можно выделить две взаимосвязанные, но и взаимоисключающие идеи, лежащие в основе понимания назначения уголовного судопроизводства - для реализации уголовного закона (борьбы с преступностью, организации уголовного преследования) или для защиты прав и свобод лиц, вовлекаемых в уголовное судопроизводство. Преобладание одной из них зависит от типа процесса, при этом на равных они существовать не могут по причине противоположных способов реализации в конкретном производстве по уголовному делу. При приоритете одной из идей весь уголовный процесс строится по типу обозначенного назначения, а вторая идея выступает одним из средств его достижения.

Назначение уголовного процесса вытекает из основных задач государства. В связи с четко установленными в Конституции РФ основными ценностями, подлежащими государственной защите, единственным назначением современного российского уголовного процесса является защита прав и свобод человека вне зависимости от его процессуального статуса в уголовном судопроизводстве.

Ключевые слова: уголовный процесс, назначение, цели, задачи, уголовное преследование, защита прав и свобод, реализация уголовного права, борьба с преступностью.

DOI: $10.35634 / 2412-9593-2021-31-2-271-276$

Отсутствие понятной и последовательной уголовно-процессуальной политики, изменяющейся в зависимости от конкретных сиюминутных задач, вектор развития уголовно-процессуального законодательства приводит к мысли о том, что в первую очередь необходимо уяснить, для чего уголовный процесс нужен в современной Российской Федерации. Следует согласиться с И.Г. Смирновой, полагающей, что назначение уголовного судопроизводства «основано на социальной потребности существования правовых норм, регулирующих отношения в сфере уголовного судопроизводства» ${ }^{1}$ При этом на различных этапах существования общества и государства эта общая потребность реализуется исходя из конкретных потребностей социума, что порождает совершенно разные подходы к пониманию назначения современного уголовного судопроизводства. Для определения четкого вектора развития уголовного процесса и правоприменения в данной сфере следует уяснить назначение современного уголовного судопроизводства в Российской Федерации.

Существует несколько в достаточной степени противоположных подходов к пониманию назначения уголовного судопроизводства. Несомненно, одним из таких является подход, уходящий своими корнями в советский уголовный процесс.

Советский подход к определению цели уголовного процесса вытекал из целей государства. Конституция СССР 1977 г. в ст. 39 четко определяла приоритет общественных интересов над интересами личности и ставила публичные рамки использования прав и свобод гражданами - оно не должно было наносить ущерб интересам общества и государства, правам других граждан.

Цели уголовного процесса нормативно определены не были, однако Уголовно-процессуальный кодекс РСФСР в ст. 2 содержал перечень задач. Уголовное судопроизводство существовало для раскрытия преступлений (быстрого и полного), изобличения виновных, правильного применения закона для того, чтобы каждый преступник был справедливо наказан и ни один невиновный не был привлечен к уголовной ответственности и не осужден (ч. 1 ст. 2 УПК РСФСР). Кроме того, отмечались указанные в рассматриваемой норме задачи разных уровней: непосредственные (указанные в ч. 1 ст. 2 УПК РСФСР) и более высокого уровня (общесоциальные) ${ }^{2}$. Причем их разрешение полагалось «есте-

\footnotetext{
${ }^{1}$ Смирнова И.Г. Социальная ценность российского уголовного судопроизводства: автореф. дис. ... докт. юрид. наук. Томск, 2012. С.25.

2 См.: Рыжаков А.П. Научно-практический комментарий к Уголовно-процессуальному кодексу РСФСР. М.: ПРИОР, 1999. С. 13-14; Якупов Р.Х. Уголовный процесс: учебник для вузов / науч. ред. В. Н. Галузо. 3-е изд., испр. и доп. М.: ТЕИС, 2001. С. 33; Уголовный процесс: учебник для студентов юридических вузов и факультетов / под ред. К.Ф. Гуценко. 4-е изд., перераб. и доп. М.: Зерцало, 2000. С. 13.
} 
ственным» при достижении непосредственных задач по большинству уголовных дел ${ }^{3}$. Эти задачи были сформулированы в ч. 2 ст. 2 УПК РСФСР и заключались в укреплении социалистической законности, правопорядка, борьбе с преступностью, охране общественных интересов, правовом воспитании граждан, уважении правил советского общежития и - в одном ряду со всеми упомянутыми охране прав и свобод граждан.

Учеными предпринимались попытки выделить, наряду с задачами, и цель (цели) уголовного процесса. При этом традиционно задачи рассматривались как конкретные цели процесса 4 .

Особенно актуальным такое разделение целей и задач стало после принятия Конституции РФ 1993 г., когда задачи, поставленные УПК РСФСР, стали противоречить новому государственному подходу - возведению прав и свобод человека в ранг высшей ценности, о чем четко и ясно указано в ст. 2 , 17, 18 Конституции РФ.

В указанной ситуации исследователи поднимались на уровень цели процесса, чтобы реализовать конституционные положения, а решение задач уголовного процесса провозглашалось в качестве механизма достижения конституционно-определенной цели. Ученые, изучавшие указанную проблему в период действия Конституции РФ и до принятия Уголовно-процессуального кодекса РФ, выделяли «двуединый» характер задач уголовного процесса, заключающийся, с одной стороны, в уголовном осуждении каждого преступника и, с другой - в непривлечении к ответственности невиновных ${ }^{5}$.

А.М. Ларин и В.М. Савицкий видели целями уголовного процесса выяснение обстоятельств совершенного преступления, виновных лиц и их наказание либо реабилитацию невиновных 6 . По мнению Н.А. Громова, главная цель уголовного судопроизводства - неосуждение того лица, в виновности которого суд не уверен ${ }^{7}$. В.Б. Алексеев указывал, что смысл, содержание и применение процессуального законодательства, а также задачи уголовного судопроизводства, как общие, так и частные, определяются необходимостью защиты от преступных посягательств на такие объекты, как жизнь, здоровье, личная свобода, честь и достоинство человека и гражданина, его жилище и имущество, иные права и законные интересы 8

Таким образом, основополагающим подходом было отношение к уголовному процессу как к деятельности, направленной на реализацию права материального, сформированное на базе понимания уголовного процесса как инструмента борьбы с преступностью.

Выделяя цель уголовного процесса на теоретическом уровне, большинство ученых не принимало во внимание противоречия, возникающие при намерении одновременно и справедливо наказать всех совершивших преступления и не допустить осуждения и привлечения к уголовной ответственности ни одного невиновного.

В то же время некоторые ученые видели и иное назначение уголовного судопроизводства. Например, И.Л. Петрухин выделял две цели уголовного процесса - «достижение истины по уголовному делу и охрану прав личности при поисках истины» ${ }^{9}$. Т.Н. Добровольская и П.С. Элькинд отмечали, что задачи уголовного процесса определяют взаимные права и обязанности субъектов уголовнопроцессуальных отношений. При этом именно соотношение интересов государства и личности выражается в конкретном объеме прав и обязанностей субъектов, вступающих в уголовно-процессуальные правоотношения ${ }^{10}$. А.Д. Прошляков отмечал неразрывное взаимное воздействие уголовно-

\footnotetext{
${ }^{3}$ Комментарий к Уголовно-процессуальному кодексу РСФСР / отв. ред. В.И. Радченко; под ред. В. Т. Томина. 3-е изд. перераб. и доп. М.: Юрайт, 1999. С. 16.

${ }^{4}$ См.: Очерк развития науки советского уголовного процесса / Н.С. Алексеев, В.Г. Даев, Л.Д. Кокорев; науч. ред. Н.С. Алексеев. Воронеж: Изд-во Воронеж. ун-та, 1980. С. 25

${ }^{5}$ Комментарий к Уголовно-процессуальному кодексу РСФСР / под ред. В.М. Савицкого, Б.Т. Безлепкина, П.А. Лупинской, И.Л. Петрухина. М.: Проспект, 1999. С. 24.

6 Савицкий В.М., Ларин А.М. Уголовный процесс: справочник. М.: Юрид. фирма «КОНТРАКТ»; ИНФРА-М, 1999. С. 180.

${ }^{7}$ Громов Н.А. Уголовный процесс России: учебное пособие. М.: Юристъ, 1999. С. 18.

${ }^{8}$ Научно-практический комментарий к Уголовно-процессуальному кодексу РСФСР / В.Б. Алексеев, В.К. Бобров, В.П. Божьев, С.В. Бородин и др.; под общ. ред. В.М. Лебедева; науч. ред. В.П. Божьев. 3-е изд., перераб. и доп. М.: Спарк, 2000. С. 22.

${ }^{9}$ Уголовный процесс: учебник / под ред. И. Л. Петрухина. М.: ПБОЮЛ Грачев С.М., 2001. С. 6.

${ }^{10}$ Юридическая процессуальная форма: теория и практика / под общ. ред. П.Е. Недбайло и В.М. Горшенева. М.: Юрид. лит., 1976. С. 238.
} 
процессуального и уголовного права ${ }^{11}$. При этом он указывал на значительные воздействия уголовнопроцессуального права на право уголовное, закона процессуального на закон материальный. Как нам представляется, если инструмент влияет на исполнителя, заставляя его менять свои намерения, он уже не является только орудием (способом реализации), а имеет свою самостоятельную, не связанную с исполнителем причину существования - назначение, которое и позволяет ему для достижения собственных целей менять существующую действительность.

Принятие УПК РФ и обозначение в его ст.6 такой категории, как «назначение» активизировали научную дискуссию по вопросу о том, зачем нужен уголовный процесс.

Представители уголовно-правовой науки традиционно назначением уголовного процесса видят реализацию норм уголовного права. Так, Д.Ю. Гончаров указывает, что «как уголовнопроцессуальные отношения предназначены для установления, реализации уголовно-правовых отношений, так же и уголовно-процессуальные нормы предназначены для реализации материальных уголовных норм» ${ }^{12}$. А.А. Васильченко считает, что уголовное право в случае его применения реализуется посредством реализации уголовно-процессуального права ${ }^{13}$, а уголовно-процессуальные отношения существуют для того, чтобы посредством реализации своих субъективных прав и обязанностей субъекты могли прийти к однозначному выводу о наличии или об отсутствии юридических фактов, предусмотренных материальными по своему характеру нормами материального права ${ }^{14}$.

Разделяет такую точку зрения и ряд процессуалистов. Так, Л.М. Володина утверждает, что «целью уголовного процесса прежде всего должна быть защита прав и законных интересов потерпевшего, защита интересов общества и государства от преступления и его последствий» ${ }^{15}$. В связи с этим назначение уголовного судопроизводства видится как защита прав и законных интересов физических и юридических лиц, потерпевших от преступления, защита интересов общества и государства, справедливое и беспристрастное правосудие, уголовное преследование лица, совершившего преступление, и назначение справедливого наказания виновному, а также отказ от уголовного преследования невиновных и их реабилитация ${ }^{16}$. Все эти положения, включаемые в содержание назначения, по сути ничем не отличаются от задач, обозначенных в УПК РСФСР, и характеризуют уголовный процесс как средство борьбы с преступностью, то есть как инструмент реализации права уголовного.

Противоположное мнение содержится в работах И.Б. Михайловской, которая отмечала, что «представление о цели уголовного процесса как средстве реализации уголовного закона не только снижает самоценность процедуры судопроизводства, но оставляет без рассмотрению ряд теоретических и практически важных проблем» ${ }^{17}$.

О.Я. Баев, критикуя желание авторов, принадлежащих к следственному ведомству, вернуться к задачам, прописанным в УПК РСФСР, предлагает в то же время включить в содержание понятия «назначение» положение о том, что реализация назначения уголовного судопроизводства «обеспечивается полным, всесторонним и объективным установлением всех подлежащих доказыванию по уголовному делу фактов и обстоятельств в условиях состязательного уголовного процесса» ${ }^{18}$.

Большинство ученых включает в содержание назначения уголовного процесса два аспекта, один из которых связан с реализацией уголовного права, а другой - с границами, в которых оно реализуется, то есть с защитой прав и свобод лиц, вовлекаемых в уголовное судопроизводство. Современное назначение уголовного судопроизводства традиционно продолжает определяться как «дву-

\footnotetext{
11 Прошляков, А.Д. Взаимосвязь материального и процессуального уголовного права: автореф. дис. ... докт. юрид. наук. Екатеринбург, 1997. С. 23.

${ }^{12}$ Гончаров Д. Ю. Взаимосвязи и коллизии норм уголовного и уголовно-процессуального законодательства: автореф. дис. ... канд. юрид. наук: 12.00.08. Екатеринбург, 2004. С. 20.

${ }^{13}$ Василиченко А. А. Взаимоотношение уголовно-правовых и уголовно-процессуальных отношений: монография. М.: Ось-89, 2006. С.106.

${ }^{14}$ Там же. С.119.

${ }^{15}$ Володина Л.М. Назначение и принципы уголовного судопроизводства - снова нравственных начал уголовнопроцессуальной деятельности // Вестник Университета им. О.Е. Кутафина (МГЮА). 2018. № 2 (42). С. 17.

${ }^{16}$ Володина Л.М. Назначение, функции и задачи уголовного судопроизводства // Известия Алтайского гос. унта. 2015. № 2-2 (86). С. 18.

17 Михайловская И.Б. Цели, функции и принципы российского уголовного судопроизводства (уголовнопроцессуальная форма). М.: ТК Велби; Проспект, 2003. С. 29.

${ }^{18}$ Баев О.Я. О принципе реализации назначения уголовного судопроизводства // Вестник Нижегородской правовой академии. 2015. № 5 (5). С. 13.
} 
единое» ${ }^{19}$. По мнению Е.В. Марковичевой и И.Г.Смирновой, «фактически российский законодатель закрепил направленность уголовного судопроизводства на разрешение уголовно-правового конфликта с соблюдением условия обеспечения прав всех лиц, вовлеченных в сферу уголовного преследования, тем самым придав правовое значение и цели, и средствам ее достижения» ${ }^{20}$.

А.С. Барабаш выделяет:

1) материально-правовое назначение уголовного процесса, выражающееся в обеспечении защиты и реализации материально-правовых интересов потерпевших и обвиняемых;

2) назначение, направленное на установление для органов государства рамок при совершении ими действий и решений по расследованию и рассмотрению уголовного дела;

3) назначение по защите государственных и общественных интересов и защите общества от преступных проявлений;

4) назначение по формированию у лица, совершившего преступление, чувства ответственности путем создания условий, обеспечивающих применение норм уголовного и уголовно-исполнительного права;

Также отмечается, что между выделенными назначениями необходимо находить баланс, не выделяя из них какие-либо за счет остальных ${ }^{21}$.

M.T. Аршибекова выделяет три предмета, защита которых является назначением уголовного судопроизводства. Первый, по ее мнению, обозначен в п. 1 ч. 1 ст. 6 УПК РФ, второй - защита личности от незаконного и необоснованного обвинения, осуждения, а третий - собственно права и интересы личности «может быть не всегда связан с существом обвинения, но определяет условия законного и обоснованного уголовного преследования» 22 . В связи с этим она выделяет особую «правообеспечительную» функцию, присущую всем субъектам, ведущим уголовный процесс, осуществляемую в интересах любого лица, вовлеченного в уголовный процесс.

Думается, что подход, в результате которого назначением процесса признается защита различных ценностей, оправдан только с формальной точки зрения - исходя из конструкции ст. 6 УПК РФ, согласно которой в содержание назначения уголовного судопроизводства включается как защита лиц, потерпевших от преступления (1), так и личности от незаконного и необоснованного обвинения, осуждения (2), ограничения ее прав и свобод (3). Попытки одновременного достижения столь разнообразных целей неизбежно порождают конфликты при реализации полномочий процессуальных органов и отсутствие единообразия при правоприменении. Как соотнести необходимость защиты личности от ограничения ее прав и свобод с необходимостью ограничить их для защиты потерпевшего от преступления (путем уголовного преследования) при том, что эти цели равнозначны? Практика показывает, что, как правило, на первое место выходит одна из обозначенных идей в ущерб остальным. Механизм достижение баланса на практике полноценно не работает.

Н.Г. Стойко, говоря о целях уголовного судопроизводства применительно к его различным типам, отмечал, что вне зависимости от типов процесса основополагающими являются «2 цели - уголовного преследования (материального права) и защиты прав и свобод (процессуального права)... Преобладание одной над другой не имеет существенного значения по причине непосредственной взаимозависимости этих целей (одна является условием достижения другой)... Цель удовлетворения частноправовых интересов (прав и свобод) является общим приоритетом в уголовных процессах сравниваемых юрисдикций» ${ }^{23}$. Поддерживая в целом данный подход, хотелось бы поспорить с несущественностью «преобладания» одной из целей. Думается, что следует, скорее, говорить о «взаимо-

\footnotetext{
${ }^{19}$ Супрун С. В. Назначение уголовного процесса и задачи уголовного права // Актуальные проблемы уголовной и уголовно-процессуальной политики Российской Федерации: материалы междунар. науч.-практ. конф. / отв. ред. И.Г. Рагозина, Ю В. Деришев. 2017. С. 187-190; Попов К. И. Назначение уголовного судопроизводства // Вестник Уральского ин-та экономики, управления и права. 2016. № 4 (37). С. 31-33.

${ }^{20}$ Марковичева Е. В., Смирнова И. Г. Борьба с преступностью и назначение уголовного судопроизводства: критерии разработки оптимальной уголовно-процессуальной стратегии в отношении несовершеннолетних // Всерос. криминолог. журнал. 2016. Т. 10, № 2. С. 341.

${ }^{21}$ Барабаш А. С. Природа российского уголовного процесса, цели уголовно-процессуальной деятельности и их установление. СПб.: Изд-во Р. Асланова «Юридический центр Пресс», 2005. С. 95-99.

${ }_{22}$ Аширбекова М. Т. Соотношение уголовно-процессуальных функций с этапами правоприменения и назначением уголовного судопроизводства // Вестник Волгоградской академии МВД России. 2015. № 4 (35). С. 93.

${ }^{23}$ Стойко Н. Г. Уголовный процесс западных государств и России: сравнительное теоретико-правовое исследование англо-американской и романо-германской правовых систем: монография. СПб.: Изд. дом СПб. гос. ун-та, Изд-во юрид. фак. СПбГУ, 2006. С. 132.
} 
дополняемости» указанных целей в общем объеме назначения уголовного процесса: чем больше одной, тем меньше другой. Так, при преобладании в объеме назначения процесса уголовного преследования на «задворках» остаются права и свободы лиц, вовлекаемых в уголовный процесс. Советский уголовный процесс, направленный на борьбу с преступностью - яркий тому пример. Еще очевиднее изменения в уголовно-процессуальном праве, связанные с чрезвычайными обстоятельствами. Уголовно-процессуальное законодательство таких периодов всегда отдает приоритет материальноправовой цели в ущерб цели уголовно-процессуальной.

Отталкиваясь от идеальных целей, присущих уголовному процессу как явлению, хочется перейти к назначению современного российского уголовного процесса. Представляется, что ключевым моментом в его определении является ст. 2 Конституции РФ. Наличие в гл. 1 Конституции РФ положений о ценностях, признаваемых и охраняемых государством, должно определять направленность и назначение всей государственной деятельности.

Задачами гражданского судопроизводства (ст. 2 ГПК РФ) являются правильное и своевременное рассмотрение и разрешение гражданских дел в целях защиты нарушенных или оспариваемых прав, свобод и законных интересов лиц, являющихся субъектами правоотношений. Согласно ст. 3 КАС РФ, задачами административного судопроизводства является защита нарушенных или оспариваемых прав, свобод и законных интересов граждан, прав и законных интересов организаций в сфере административных и иных публичных правоотношений. Задачами судопроизводства в арбитражных судах, согласно ст. 2 АПК РФ, является защита нарушенных или оспариваемых прав и законных интересов лиц, осуществляющих предпринимательскую и иную экономическую деятельность, а также иных субъектов в указанной сфере. Иные обозначенные в рассматриваемых процессуальных кодексах задачи представляются сопутствующими главной цели - защите прав человека. Таким образом, задачи упомянутых процессуальных отраслей права в большей степени вытекают из конституционной обязанности государства по защите прав и свобод человека.

Из рассмотренной тенденции выпадает КоАП РФ, где в ст. 24.1. в лучших советских традициях определено, что «задачами производства по делам об административных правонарушениях являются всестороннее, полное, объективное и своевременное выяснение обстоятельств каждого дела, разрешение его в соответствии с законом, обеспечение исполнения вынесенного постановления, а также выявление причин и условий, способствовавших совершению административных правонарушений».

В отношении процесса уголовного следует отметить, что специфика отрасли, возможности государственного вмешательства в частную жизнь в данной сфере в большей, чем в иных процессуальных отраслях, степени требует от нее подъема от механизма репрессии (реализации норм уголовного права) до гарантии обеспечения прав и свобод человека. Думается, такой подход и привел к нормативному закреплению в УПК РФ не «задач» процесса (как в иных отраслях), а именно его «назначения», то есть переходу на качественный иной уровень.

При рассмотрении уголовного процесса как способа реализации посредством уголовнопроцессуального инструментария основной обязанности государства (по признанию, соблюдению и защите прав и свобод человека и гражданина ${ }^{24}$ ) становится очевидным приоритет (из числа ранее названных «идеальных» целей) процессуальной цели над целью материальной. И это приоритет абсолютный, делающий вторую цель инструментом достижения единственного назначения уголовного процесса - защиты прав и свобод человека.

Учитывая приоритет правоотношений по защите прав и свобод личности по отношению к уголовно-процессуальным правоотношениям, неоднократно подчеркиваемый Конституционным Судом РФ, следует отметить, что уровень защиты прав и свобод человека не может зависеть от процессуального положения лица, вовлеченного в уголовный процесс: и свидетель, и обвиняемый, и потерпевший, и понятой имеют одинаковые гарантии защиты их прав при производстве по уголовному делу. Процессуальный статус играет значительную роль в определении объема защищаемых государством прав и свобод 25 , однако не имеет значения касательно общей посылки данной защиты - назначения уголовного процесса как реализации задачи, поставленной Конституцией РФ.

Поступила в редакцию 23.01.2021

\footnotetext{
${ }^{24}$ См.: Лазарева В.А. Уголовный процесс как способ защиты прав и свобод человека и гражданина (назначение уголовного судопроизводства) // LEX RUSSICA ( Научные труды МГЮА). 2010. № 3. С. 540-550.

${ }^{25}$ См.: Максимов О.А. Индивидуальный статус участника уголовного процесса, как необходимое условие полноценной уголовно-процессуальной деятельности // Полицейская и следственная деятельность. 2018. № 2. С. 1-8.
} 
Максимов Олег Александрович, кандидат юридический наук, доцент, заведующий кафедрой уголовного процесса ФГБОУ «Ульяновский государственный университет» 432000, Россия г. Ульяновск, ул. Льва Толстого, 42

E-mail: omaksimov@mail.ru

\section{O.A. Maksimov}

\section{ON THE APPOINTMENT OF THE MODERN RUSSIAN CRIMINAL PROCESS}

DOI: $10.35634 / 2412-9593-2021-31-2-271-276$

The article examines the purpose of the modern Russian criminal procedure as a way of implementing the constitutionally defined tasks of the state.

With a variety of approaches to defining the subject of research, one can single out two interrelated, but also mutually exclusive ideas that underlie the understanding of the purpose of criminal proceedings - for the implementation of criminal law (combating crime, organizing criminal prosecution) or for protecting the rights and freedoms of persons involved in criminal proceedings. legal proceedings. The prevalence of one of them depends on the type of process, while they cannot exist on equal terms due to the opposite methods of implementation in a particular criminal proceeding. With the priority of one of the ideas, the entire criminal process is built according to the type of designated purpose, and the second idea is one of the means of achieving it.

The purpose of the criminal procedure follows from the main tasks of the state. It is concluded that in connection with the clearly established in the Constitution the basic values subject to state protection, the only purpose of the modern Russian criminal procedure is to protect human rights and freedoms, regardless of his procedural status in criminal proceedings.

Keywords: criminal procedure, appointment, goals, objectives, criminal prosecution, protection of rights and freedoms, implementation of criminal law, combating crime.

Received 23.01.2021

Maksimov O.A., Candidate of Law, Associate Professor, Head of Department of Criminal Procedure Ulyanovsk State University

L. Tolstogo st., 42, Ul'yanovsk, Russia, 432000

E-mail: omaksimov@mail.ru 